\title{
Theoretical Study of Structural and Electronic Properties of Methyl Silsesquioxanes
}

\author{
Ruth Franco, ${ }^{\dagger}$ Anil K. Kandalam, and Ravindra Pandey* \\ Department of Physics, Michigan Technological University, Houghton, Michigan 49931
}

\author{
Udo C. Pernisz \\ Dow Corning Corporation, Midland, Michigan 48686 \\ Received: July 17, 2001; In Final Form: December 11, 2001
}

\begin{abstract}
Calculations based on density functional theory (DFT) were performed on various structural isomers of methyl silsesquioxanes, $\left[\mathrm{MeSiO}_{3 / 2}\right]_{n}$ where $n=4,6,8,10,12,14$, and 16 , to study their structural and electronic properties. The calculated results find the stability of methyl silsesquioxanes, except $\left[\mathrm{MeSiO}_{3 / 2}\right]_{4}$, against fragmentation and hydrolysis, and of one isomer of $\left[\mathrm{MeSiO}_{3 / 2}\right]_{14}$ against hydrolysis. The deformation density plots show that chemical bonding in methyl silsesquioxanes is mainly determined by the building block unit, $\left(\mathrm{MeSiO}_{3 / 2}\right)$ as also seen in hydridosilsesquioxanes (HSQ). However, unlike HSQ, the large cages of methyl silsesquioxanes do not develop a localized electronic state in the HOMO-LUMO gap.
\end{abstract}

\section{Introduction}

Spherosiloxane molecules have been a subject of various theoretical and experimental studies because of their applications in the microelectronic industry. One example is the $\mathrm{H}$ silsesquioxanes (HSQ), which constitute a class of inorganic polymer resins and have become a material of choice in semiconductor manufacturing for gap filling and planarization and as an interlayer dielectric., ${ }^{1,2}$ Research into electronic properties of silsesquioxane thin films has revealed an electric bistability of the material. ${ }^{3}$ In a theoretical work to identify the electronic origin of states that could induce such a conductivity, we have analyzed the series of silsesquioxane molecules $\left[\mathrm{HSiO}_{3 / 2}\right]_{n}$ where $n=4,6,8,10,12,14$, and 16 , determining their lowest-energy isomeric conformations, their stability against hydrolysis and fragmentation, and also their linear and nonlinear optical properties. ${ }^{4,5}$ It was found that for cages with $n=14$ and 16 an electronic mid-gap state appears in the otherwise large HOMO-LUMO gap because of contributions from hydrogen bonded to silicon atoms.

While a direct link between the mid-gap states of the $\left[\mathrm{HSiO}_{3 / 2}\right]_{14}$ and $\left[\mathrm{HSiO}_{3 / 2}\right]_{16}$ cages and the bistability of the silsesquioxane resin films has not yet been established, we set out to first understand the effect of substituting the hydrogen by other functional groups such as methyl or phenyl on the electronic properties. For example, monosubstituted $\mathrm{PhH}_{7} \mathrm{Si}_{8} \mathrm{O}_{12}$ and $\mathrm{PhH}_{9} \mathrm{Si}_{10} \mathrm{O}_{15}$ were prepared and characterized by IR and Raman spectroscopy. ${ }^{6}$ The phenyl substituent was not found to modify the frequency range of the parent molecules. X-ray photoelectron spectroscopy was used to study the valence band regions of methyl and phenyl silsesquioxanes. The methyl groups were found to contribute in the inner valence region of the spectrum, whereas contributions from the phenyl group also appeared in the outer valence region of the spectrum. ${ }^{7}$ Effects of methyl substitution on the electronic properties of $\mathrm{HSiO}_{3 / 2}$, however, were not investigated.

\footnotetext{
* To whom correspondence should be addressed.

† Permanent address: Departamento de Química Física y Analítica, Universidad de Oviedo, 33006-Oviedo, Spain.
}

In this paper, we report the results of a theoretical study of the structural and electronic properties of methyl silsesquioxanes. Analogous to HSQ molecules, the building block of methyl silsesquioxanes is $\left[\mathrm{CH}_{3} \mathrm{SiO}_{3 / 2}\right]$ referred to as $[\mathrm{MeT}]$ in the following discussion. In this nomenclature, the symbol $\mathrm{T}$ represents the trifunctional unit $\left[\mathrm{SiO}_{3 / 2}\right]$.

The rest of the paper is organized as follows: In section II, we describe the computational method employed in this work. Results and discussion of the geometrical features and stability against fragmentation and hydrolysis are presented in section III. The electronic properties of the lowest-energy isomers of various methyl silsesquioxane cages are also given in this section. Finally, our conclusions will be given in section IV.

\section{Computational Method}

All electron calculations were performed within the framework of density functional theory (DFT). The gradient-corrected (GGA) functional, by Perdew and Wang, ${ }^{8}$ as implemented in the $\mathrm{DMol}^{9}$ program, was employed here. The double numerical basis set (DNP), ${ }^{10}$ supplemented with diffuse and polarization functions, was used for all atoms $(\mathrm{C}, \mathrm{H}, \mathrm{Si}$, and $\mathrm{O})$. The accuracy of the basis set has been analyzed in detail in our previous study on H-silsesquioxanes. ${ }^{4}$ In the present calculations, the density tolerance was set to $10^{-5} \mathrm{e} / \mathrm{bohr}^{3}$. The geometric parameters were fully optimized under the given symmetry group with a convergence criterion for the energy tolerance and maximum gradient component of less than $10^{-3}$ hartree and $10^{-3}$ hartree/ bohr, respectively. It is to be noted here that the calculated results correspond to the singlet spin state of methyl silsesquioxanes.

To describe the configurations of methyl silsesquioxanes considered for calculations, we follow the convention of Agaskar and Klemperer, ${ }^{11}$ who used the notation of $N^{n}$ to represent $n$ $\mathrm{N}$-member rings in $\mathrm{H}$-silsesquioxanes. For example, the $[\mathrm{MeT}]_{14}$ cage may have isomeric configurations given by $6^{0} 5^{6} 4^{3}$ (six fivemember and three four-member rings), $6{ }^{1} 5^{4} 4^{4}$ (one six-member, four five-member, and four four-member rings), $6^{2} 5^{2} 4^{6}$ (two six-member, two five-member, and six four-member rings), and 

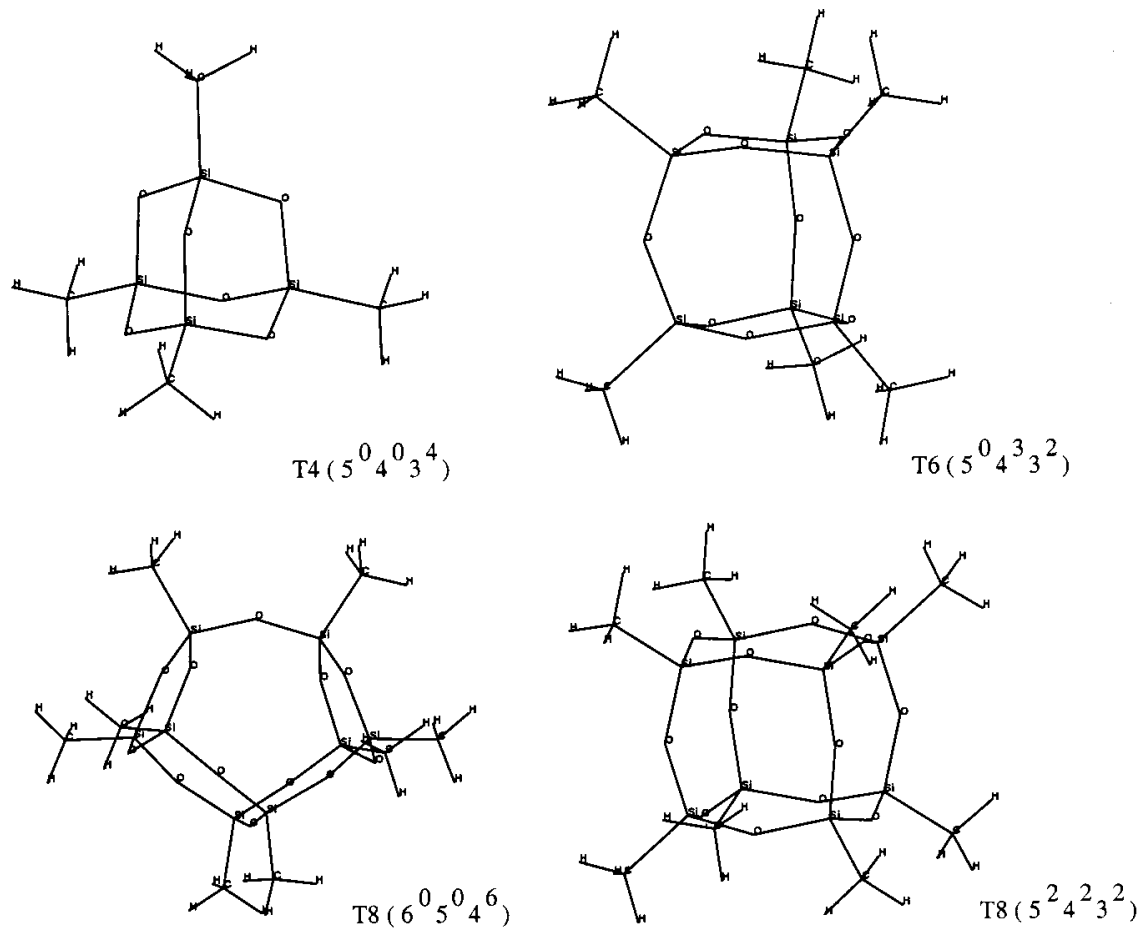

Figure 1. Optimized configurations of $[\mathrm{MeT}]_{4},[\mathrm{MeT}]_{6}$, and $[\mathrm{MeT}]_{8}$.
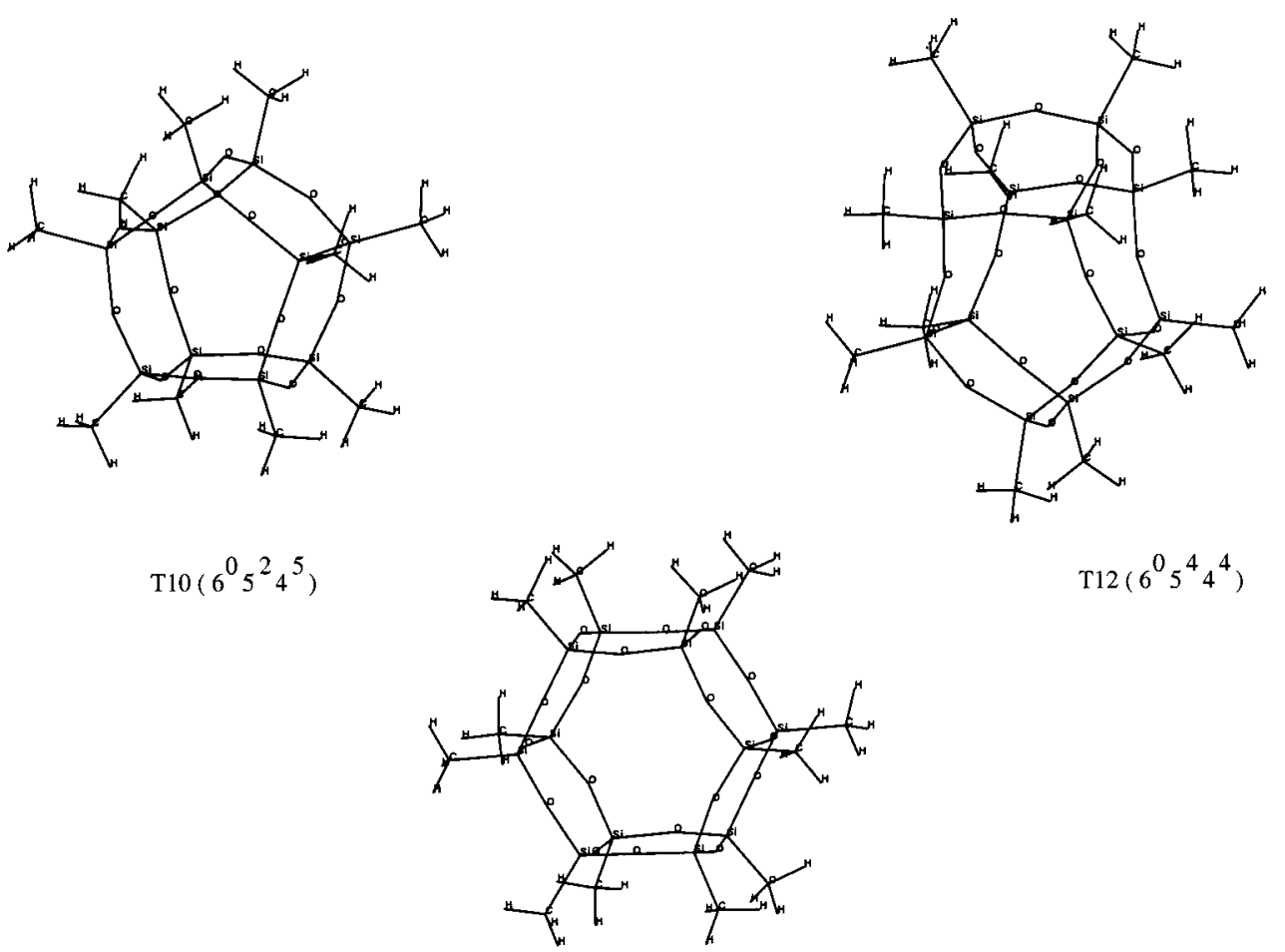

$\mathrm{T} 12\left(6^{0} 5^{4} 4^{4}\right)$

$$
\operatorname{T} 12\left(6^{2} 5^{0} 4^{6}\right)
$$

Figure 2. Optimized configurations of $[\mathrm{MeT}]_{10}$ and $[\mathrm{MeT}]_{12}$.

$6^{3} 5^{0} 4^{6}$ (three six-member and six four-member rings). Not all of the possible isomers of a given methyl silsesquioxane were considered for calculations. The choice of isomers for the present study was based on the results of our previous study ${ }^{4}$ on $\mathrm{H}$-silsesquioxanes. Here, $[\mathrm{MeT}]_{4},[\mathrm{MeT}]_{6}$, and $[\mathrm{MeT}]_{10}$ cages are represented by a single configuration, whereas $[\mathrm{MeT}]_{8}$, $[\mathrm{MeT}]_{12},[\mathrm{MeT}]_{14}$, and $[\mathrm{MeT}]_{16}$ cages are represented by multiple isomeric configurations differing in the number of four-, five-, and six-member rings. Overall, this choice is expected to reveal the dependence of the structural and electronic properties on the cage size of methyl silsesquioxane in a consistent and systematic way.

\section{Results and Discussion}

The optimized configurations for the methyl silsesquioxanes in this work are given in Figures 1-4, whereas Table 1 shows 

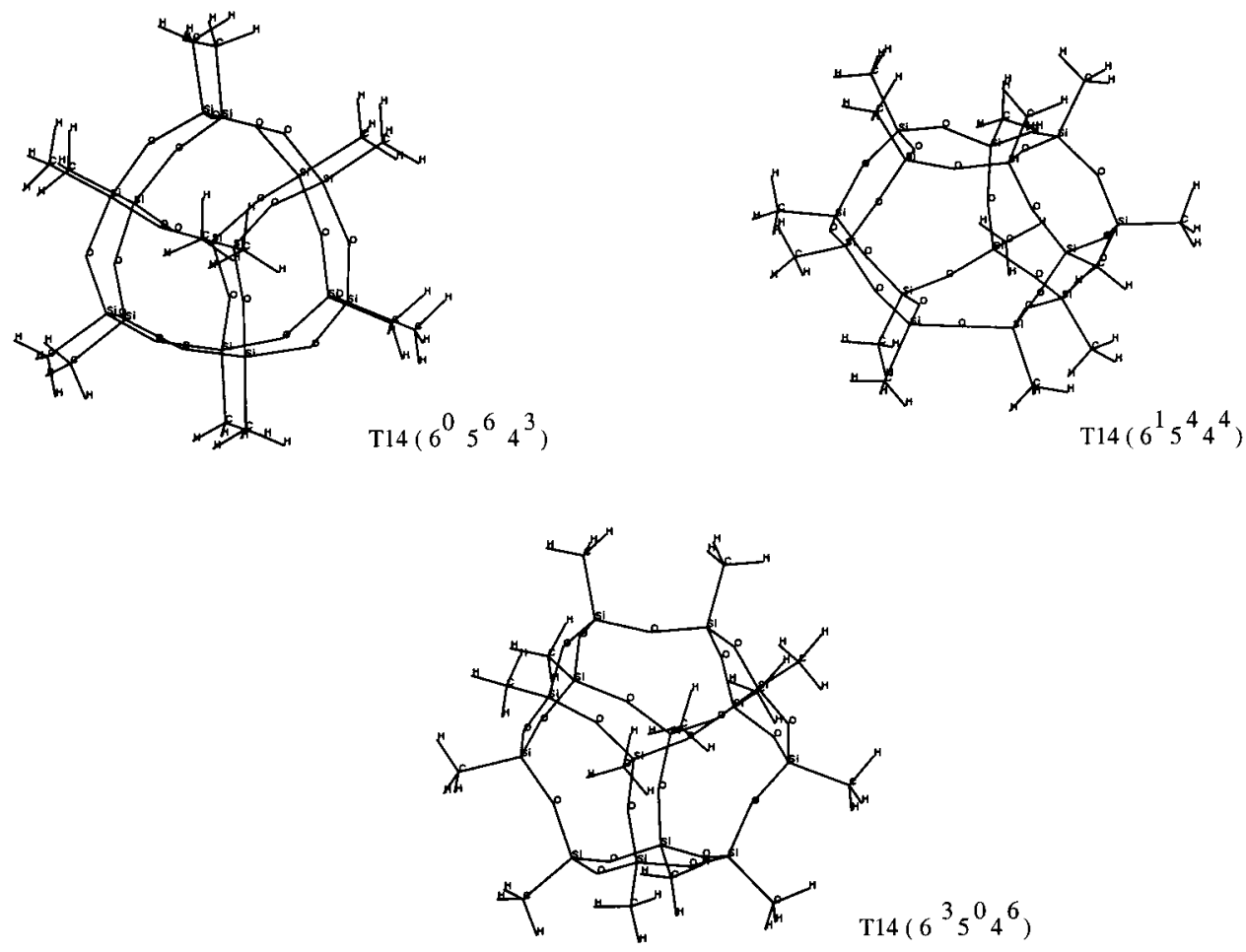

Figure 3. Optimized configurations of $[\mathrm{MeT}]_{14}$.
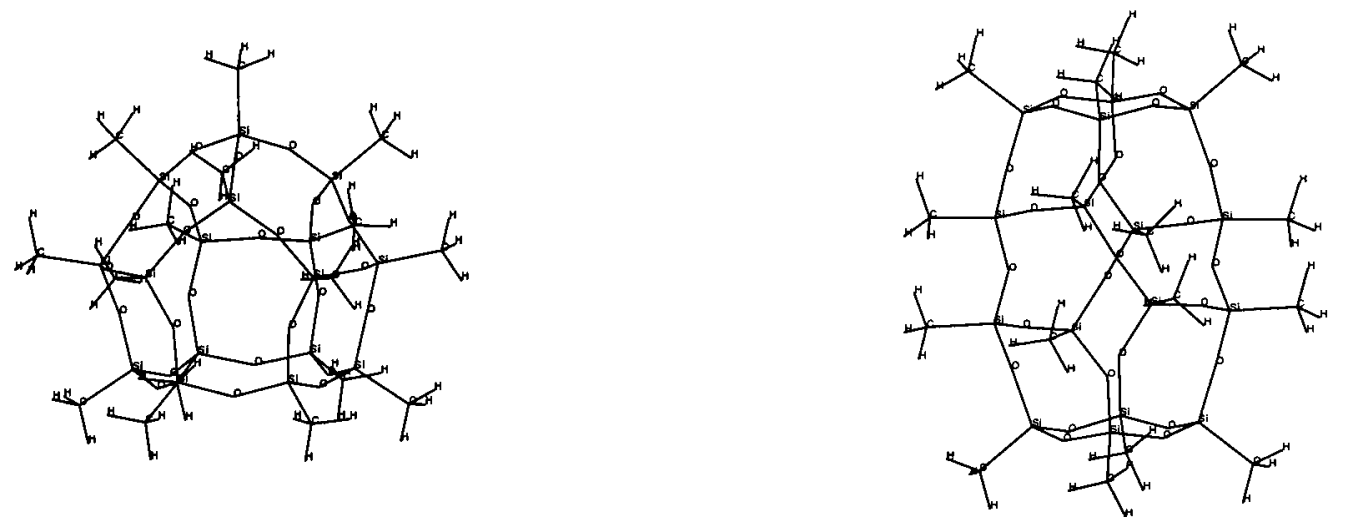

$\mathrm{T} 16\left(6^{0} 5^{8} 4^{2}\right)$

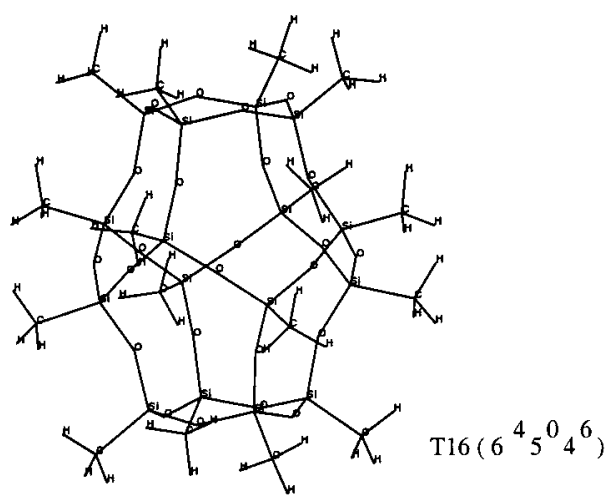

$\mathrm{T} 16\left(6^{1} 5^{6} 4^{3}\right)$

Figure 4. Optimized configurations of $[\mathrm{MeT}]_{16}$.

their corresponding calculated energies. The structural parameters including bond lengths and bond angles of the optimized configurations can be obtained from the corresponding author (pandey@mtu.edu). Calculations for larger methyl silsesquioxanes (i.e., $n>10$ ) were performed using $C_{1}$ symmetry.

The calculated relative energy per silicon atom with respect to the smallest methyl silsesquioxane (i.e., $[\mathrm{MeT}]_{4}$ ) shows, in general, an increasing stability of $[\mathrm{MeT}]_{n}$, except for $[\mathrm{MeT}]_{14}$ $\left(6^{3} 5^{0} 4^{6}\right)$. It also appears that a larger ring size is preferred with the increase in the cage size of $[\mathrm{MeT}]_{n}$. For example, $[\mathrm{MeT}]_{8}$ prefers the $4^{6}$ configuration over the $5^{2} 4^{2} 3^{2}$ configuration. On the other hand, the $6^{1} 5^{6} 4^{3}$ configuration is predicted to be most stable for $[\mathrm{MeT}]_{16}$ in this work.

The bond lengths in all of the optimized isomeric configurations (i.e., $R_{\mathrm{Si}-\mathrm{O}}, R_{\mathrm{Si}-\mathrm{C}}$ and $R_{\mathrm{C}-\mathrm{H}}$ ) do not show any size dependence, as expected. However, the bond angle $A_{\mathrm{Si}-\mathrm{O}-\mathrm{Si}}$ for a given $[\mathrm{MeT}]_{n}$ shows a large variation in going from fourmember rings to six-member rings, accommodating more atoms. 
TABLE 1: Composition and Calculated Energies of Isomers of Methyl Silsesquioxanes

\begin{tabular}{|c|c|c|c|c|c|c|}
\hline & composition & sym & $\begin{array}{l}\text { total energy, } \\
\text { hartree }\end{array}$ & $\begin{array}{l}\mathrm{BE} \mathrm{Si} \text {, } \\
\mathrm{kcal} / \mathrm{mol}\end{array}$ & $\begin{array}{l}\text { relative energy } \\
\mathrm{Si}, \mathrm{kcal} / \mathrm{mol}\end{array}$ & $\begin{array}{c}\text { energy of hydrolysis } \\
\mathrm{Si}, \mathrm{kcal} / \mathrm{mol}\end{array}$ \\
\hline$[\mathrm{MeT}]_{4}\left(\left(\mathrm{CH}_{3}\right)_{4} \mathrm{Si}_{4} \mathrm{O}_{6}\right)$ & $5^{0} 4^{0} 3^{4}$ & $C_{2 v}$ & -1769.6998 & 721.13 & 0.0 & -4.30 \\
\hline$[\mathrm{MeT}]_{6}\left(\left(\mathrm{CH}_{3}\right)_{6} \mathrm{Si}_{6} \mathrm{O}_{9}\right)$ & $5^{0} 4^{3} 3^{2}$ & $C_{S}$ & -2654.6141 & 727.84 & -6.7 & 2.42 \\
\hline \multirow[t]{2}{*}[\mathrm{MeT}]{$_{8}\left(\left(\mathrm{CH}_{3}\right)_{8} \mathrm{Si}_{8} \mathrm{O}_{12}\right)$} & $6^{0} 5^{0} 4^{6}$ & $C_{4 v}$ & -3539.4995 & 728.91 & -7.8 & 3.53 \\
\hline & $5^{2} 4^{2} 3^{2}$ & $C_{S}$ & -3539.4943 & 728.54 & -7.4 & 3.12 \\
\hline$[\mathrm{MeT}]_{10}\left(\left(\mathrm{CH}_{3}\right)_{10} \mathrm{Si}_{10} \mathrm{O}_{15}\right)$ & $6^{0} 5^{2} 4^{5}$ & $C_{1}$ & -4424.3788 & 729.23 & -8.1 & 3.80 \\
\hline \multirow[t]{2}{*}[\mathrm{MeT}]{$_{12}\left(\left(\mathrm{CH}_{3}\right)_{12} \mathrm{Si}_{12} \mathrm{O}_{18}\right)$} & $6^{0} 5^{4} 4^{4}$ & $C_{1}$ & -5309.2539 & 729.16 & -8.1 & 3.77 \\
\hline & $6^{2} 5^{0} 4^{6}$ & $C_{S}$ & -5309.2423 & 728.60 & -7.5 & 3.16 \\
\hline \multirow[t]{3}{*}[\mathrm{MeT}]{$_{14}\left(\left(\mathrm{CH}_{3}\right)_{14} \mathrm{Si}_{14} \mathrm{O}_{21}\right)$} & $6^{0} 5^{6} 4^{3}$ & $C_{1}$ & -6194.1302 & 729.23 & -8.1 & 3.80 \\
\hline & $6^{1} 5^{4} 4^{4}$ & $C_{1}$ & -6194.1258 & 729.04 & -7.9 & 3.60 \\
\hline & $6^{3} 5^{0} 4^{6}$ & $C_{1}$ & -6193.5231 & 701.55 & +19.1 & -22.80 \\
\hline \multirow[t]{3}{*}[\mathrm{MeT}]{$_{16}\left(\left(\mathrm{CH}_{3}\right)_{16} \mathrm{Si}_{16} \mathrm{O}_{24}\right)$} & $6^{0} 5^{8} 4^{2}$ & $C_{1}$ & -7078.9952 & 728.79 & -7.7 & 3.38 \\
\hline & $6^{1} 5^{6} 4^{3}$ & $C_{1}$ & -7079.0043 & 729.16 & -8.0 & 3.73 \\
\hline & $6^{4} 5^{0} 4^{6}$ & $C_{1}$ & -7078.9950 & 728.79 & -7.7 & 3.37 \\
\hline
\end{tabular}

TABLE 2: Fragmentation Energies for the Lowest Energy Isomers of Methyl Silsesquioxanes

\begin{tabular}{lc}
\hline & $E(\mathrm{kcal} / \mathrm{mol})$ \\
\hline$[\mathrm{MeT}]_{8} \rightarrow[\mathrm{MeT}]_{4}+[\mathrm{MeT}]_{4}$ & 62.6 \\
{$[\mathrm{MeT}]_{10} \rightarrow[\mathrm{MeT}]_{6}+[\mathrm{MeT}]_{4}$} & 40.7 \\
{$[\mathrm{MeT}]_{12} \rightarrow[\mathrm{MeT}]_{4}+[\mathrm{MeT}]_{4}+[\mathrm{MeT}]_{4}$} & 96.9 \\
{$[\mathrm{MeT}]_{12} \rightarrow[\mathrm{MeT}]_{8}+[\mathrm{MeT}]_{4}$} & 34.2 \\
{$[\mathrm{MeT}]_{12} \rightarrow[\mathrm{MeT}]_{6}+[\mathrm{MeT}]_{6}$} & 16.1 \\
{$[\mathrm{MeT}]_{14} \rightarrow[\mathrm{MeT}]_{6}+[\mathrm{MeT}]_{4}+[\mathrm{MeT}]_{4}$} & 73.1 \\
{$[\mathrm{MeT}]_{14} \rightarrow[\mathrm{MeT}]_{10}+[\mathrm{MeT}]_{4}$} & 32.4 \\
{$[\mathrm{MeT}]_{14} \rightarrow[\mathrm{MeT}]_{8}+[\mathrm{MeT}]_{6}$} & 10.4 \\
{$[\mathrm{MeT}]_{16} \rightarrow[\mathrm{MeT}]_{8}+[\mathrm{MeT}]_{4}+[\mathrm{MeT}]_{4}$} & 66.0 \\
{$[\mathrm{MeT}]_{16} \rightarrow[\mathrm{MeT}]_{6}+[\mathrm{MeT}]_{6}+[\mathrm{MeT}]_{4}$} & 47.9 \\
{$[\mathrm{MeT}]_{16} \rightarrow[\mathrm{MeT}]_{12}+[\mathrm{MeT}]_{4}$} & 31.7 \\
{$[\mathrm{MeT}]_{16} \rightarrow[\mathrm{MeT}]_{10}+[\mathrm{MeT}]_{6}$} & 7.2 \\
{$[\mathrm{MeT}]_{16} \rightarrow[\mathrm{MeT}]_{8}+[\mathrm{MeT}]_{8}$} & 3.3
\end{tabular}

A similar variation was predicted in our previous study on H-silsesquioxanes.

In the presence of hydroxyl groups, methyl silsesquioxanes can undergo a hydrolysis reaction as follows:

$$
\left(\left(\mathrm{CH}_{3}\right) \mathrm{SiO}_{3 / 2}\right)_{n}+\left(\frac{3}{2}\right) n \mathrm{H}_{2} \mathrm{O} \rightarrow n\left(\mathrm{CH}_{3}\right) \mathrm{Si}(\mathrm{OH})_{3}
$$

The hydrolysis reaction is an endothermic process for all $[\mathrm{MeT}]_{n}$, except for $[\mathrm{MeT}]_{4}$ and an isomer of $[\mathrm{MeT}]_{14}$. The reaction energy per silicon atom (Table 1) remains approximately constant with a value of about $3.5 \mathrm{kcal} / \mathrm{mol}$ in going from $[\mathrm{MeT}]_{8}$ to $[\mathrm{MeT}]_{16}$. It may be noted here that the energy of this reaction depends on the binding energy and therefore it follows a trend similar to that of the binding energy. The binding energy per silicon atom slightly increases from $[\mathrm{MeT}]_{4}$ to $[\mathrm{MeT}]_{8}$ and thereafter remains nearly constant with a value of $729 \mathrm{kcal} /$ mol.

We have also assessed the stability of the lowest-energy isomers of methyl silsesquioxanes by calculating the fragmentation energy for all possible pathways (see Table 2). The methyl silsesquioxanes considered here are, therefore, predicted to be stable, although their stability appears to be decreasing with the increase in their size. For example, the fragmentation of $[\mathrm{MeT}]_{8}$ would require about $62.6 \mathrm{kcal} / \mathrm{mol}$, whereas that of $[\mathrm{MeT}]_{16}$ would need only $3.3 \mathrm{kcal} / \mathrm{mol}$. We note here that these calculations are based on the total energy of the most stable configurations of $[\mathrm{MeT}]_{n}$.

The HOMO-LUMO gap remains nearly constant ranging from $7.27 \mathrm{eV}$ for $[\mathrm{MeT}]_{6}$ to $6.73 \mathrm{eV}$ for $[\mathrm{MeT}]_{16}$. Unlike hydridosilsesquioxanes, methyl silsesquioxanes do not reveal the presence of any localized electronic state in the HOMOLUMO gap. This finding is relevant to the application of the silsesquioxanes as an interlayer dielectric material in integrated circuits because the insulating properties of a material with a conductive state may be inadequate for device performance. On the other hand, the control of conductive states in the energy gap of wide-gap semiconductors by chemical structure, rather than by elemental doping, is desirable for the development of novel materials.

The lone-pair p-type atomic orbitals of oxygen atoms form HOMOs as shown in Figure 5, while a combination of atomic orbitals associated with $\mathrm{Si}, \mathrm{O}, \mathrm{C}$, and $\mathrm{H}$ form LUMOs. For example, the HOMO region starts at about $-6.9 \mathrm{eV}$ in $[\mathrm{MeT}]_{8}$, which is closely followed by levels in the region between -7.5 and $-8.2 \mathrm{eV}$. All are formed by lone-pair oxygen p-type atomic
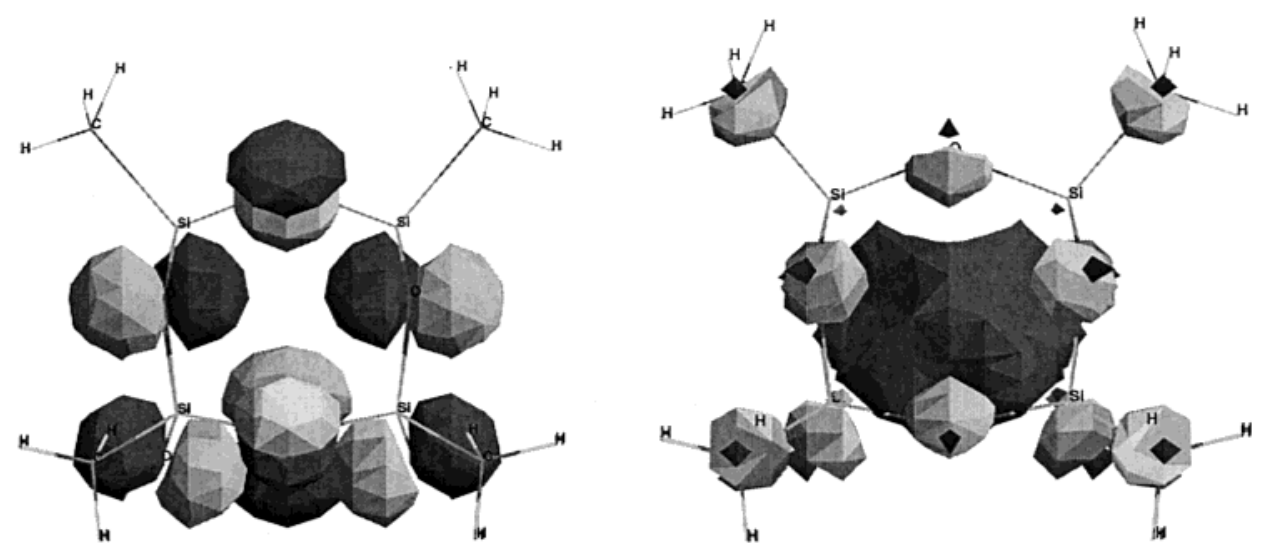

Figure 5. HOMO (left) and LUMO (right) contours for $[\mathrm{MeT}]_{6}$. Negative (dark solid contours) and positive (light solid contours) regions are plotted with contours of $0.03 \mathrm{e}^{\mathrm{bohr}}{ }^{3}$. (It is to be noted here that the surface appearing on the top of the LUMO (negative region), is not an open surface but a software-related artifact.) 

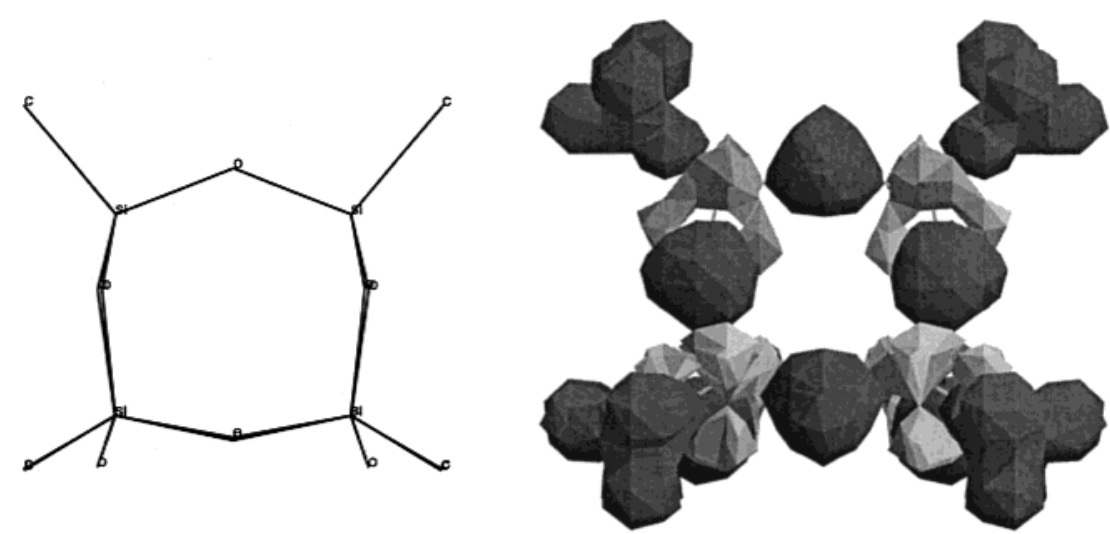

Figure 6. Deformation electronic density maps for $[\mathrm{MeT}]_{6}$. Negative (dark solid contours) and positive (light solid contours) regions represent zones of surplus and depleted electronic density, respectively, and are plotted with contours of $0.01 \mathrm{e} / \mathrm{bohr}^{3}$.

orbitals, with weak interactions of the $\mathrm{C}, \mathrm{H}$, and $\mathrm{Si}$ atomic orbitals. The next orbitals are found in the region between -8.9 and $-10.9 \mathrm{eV}$, where the contribution of the methyl group $\left(\mathrm{CH}_{3}\right)$ was observed. The results of our calculations are in agreement with the experimental and simulated spectra of poly(methyl silsesquioxane) showing a peak in the region of $6-11 \mathrm{eV}$ due to oxygen. ${ }^{7}$

The deformation electronic density maps generally illustrate the electronic distribution in the bond formation of any molecule. For the methyl cages, Mulliken population analysis indicates a charge transfer from $\mathrm{Si}$ to $\mathrm{O}$ atoms associating a charge of $+1.6 e$ to $\mathrm{Si}$ and $-0.9 e$ to $\mathrm{O}$ atoms in the cages considered here. Such a charge transfer is shown in a density map displayed in Figure 6 for $[\mathrm{MeT}]_{6}$ in which deviations from sphericity of the electron clouds are clearly seen. Like $\left(\mathrm{HSiO}_{3 / 2}\right)_{6}$ cages, Mulliken charges associated with $\mathrm{Si}$ and $\mathrm{O}$ atoms in the methyl cages do not show any size dependence suggesting that the nature of the chemical bonding in methyl silsesquioxanes is mainly determined by their buliding block, $\left[\mathrm{MeSiO}_{3 / 2}\right]$.

\section{Conclusions}

In summary, we have performed first-principles calculations on various structural isomers of methyl silsesquioxanes, $\left[\mathrm{MeSiO}_{3 / 2}\right]_{n}$ where $n=4,6,8,10,12,14$, and 16 , to study their structural and electronic properties. The calculated results predict the stability of isolated methyl silsesquioxanes, except $\left[\mathrm{MeSiO}_{3 / 2}\right]_{4}$, against fragmentation and hydrolysis.
Acknowledgment. The authors acknowledge helpful discussions with Dr. Christoph Eggs. A.K. acknowledges the award of a Dow Corning fellowship, and R.F. acknowledges the financial support of the Spanish Secretaría de Estado de Universidades, Investigación y Desarollo and Spanish DGICyT for Grants PB96-0559 and BQU2000-0466. This project is also supported by Molecular Simulations Inc., San Diego (now, Accelrys, a subsidiary of Pharmacopeia Inc.).

\section{References and Notes}

(1) Corriu, R., Corriu, P., Jutzi, P., Eds. G. Calzaferri: Tailor-made silicon oxygen compounds: from molecules to materials; Braunschweig: Wiesbaden, Germany, 1996.

(2) Frye, C. L.; Collins, W. T. J. Am. Chem. Soc. 1990, 92, 5586.

(3) Pernisz, U. C. Electroceramics IV, Proceedings of the 4th International Conference on Electronic Ceramics and Applications, Aachen; Waser, P., Ed.; Augustinus Buchhandlung: Aachen, Germany, 1994; Vol. II., p 823.

(4) Xiang, K.-H.; Pandey, R.; Pernisz, U. C.; Freeman, C. J. Phys. Chem. B 1998, 102, 8704.

(5) Cheng, W.-D.; Xiang, K.-H.; Pandey, R.; Pernisz, U. C. J. Phys Chem. B 2000, 104, 6737.

(6) Calzaferri, G.; Marcolli, C.; Imhof, R.; Tornroos, K. W. J. Chem. Soc., Dalton Trans. 1996, 3313.

(7) Ferenczy, G. G.; Tóth, A.; Bertóti, I.; Suhai, S. J. Phys.: Condens. Matter 1997, 9, 4781.

(8) Perdew, J. P.; Chevary, J.; Vosko, S.; Jackson, K. A.; Pederson, M. R.; Singh, D. J.; Fiolhais, C. Phys. Rev. B 1992, 46, 6671.

(9) Delly, B. J. Chem. Phys. 1990, 92, 508.

(10) Rosen, A.; Ellis, D. E.; Adachi, H.; Averill, F. W. J. Chem. Phys. 1976, 65, 3629 .

(11) Agaskar, P. A.; Klemperer, W. G. Inorg. Chim. Acta 1995, 229, 335. 